\title{
Targeting the PI3K/Akt/mTOR pathway for breast cancer therapy
}

\author{
Justin Cidado ${ }^{1}$ and Ben Ho Park ${ }^{1}$ \\ ${ }^{1}$ The Sidney Kimmel Comprehensive Cancer Center at Johns Hopkins, Baltimore, MD
}

\begin{abstract}
Recent advances in genetics and genomics have revealed new pathways that are aberrantly activated in many breast cancers. Chief among these genetic changes are somatic mutations and/or gains and losses of key genes within the phosphoinositide 3-kinase (PI3K) pathway. Since breast cancer cell growth and progression is often dependent upon activation of the PI3K pathway, there has been intense research interest in finding therapeutic agents that can selectively inhibit one or more constituents of this signaling cascade. Here we review key molecules involved with aberrant PI3K pathway activation in breast cancers and current efforts to target these components for therapeutic gain.
\end{abstract}

\section{Introduction}

Breast cancer is the second most common malignancy diagnosed in women and the second leading cause of cancer-related deaths. It is a heterogeneous disease often characterized by its hormone receptor status and expression of human epidermal growth factor receptor 2 (Her2). These molecular markers used to classify breast cancer subtypes are also what typically predict response to targeted therapies. Thus, identifying novel breast cancer targets and developing diagnostic biomarkers in order to provide early and effective therapy remains of paramount importance.

To date, a number of therapies have been developed to specifically inhibit crucial oncogenic targets in a variety of cancers. For breast cancers in particular, endocrine therapies such as the selective estrogen receptor modulator (SERM), tamoxifen, antagonizes estrogen receptor-a (ER) in ER(+) cancers while the humanized monoclonal antibody, trastuzumab, inhibits receptor signaling in HER2-amplified/overexpressing cancers. Each therapy achieves a relatively high response rate in their respective patient populations, but an equally and discouragingly high number of patients become refractory to the treatment over time.

Recently, biological studies point to aberrant PI3K/Akt/mTOR signaling pathway (hereafter referred to as PI3K signaling pathway) activation as central for cancer growth, survival, and motility as well as targeted therapy resistance mechanisms [1-4]. Consequently, heavy emphasis on PI3K signaling research has led to the development of numerous pathway inhibitors [5]. Here we will review the recent progress in pharmacological intervention of the PI3K pathway including its rationale, limitations, and methods of patient stratification.

Corresponding Author/Address for reprints: Ben Ho Park, M.D., Ph.D. The Sidney Kimmel Comprehensive Cancer Center at Johns Hopkins 1650 Orleans Street, Rm 151 Baltimore, MD 21287 Phone: 410-502-7399 Fax: 410-614-4073 bpark2@jhmi.edu. 


\section{PI3K-Akt-mTOR signaling cascade}

\section{Normal signaling}

The family of phosphoinositide 3-kinases (PI3K) consist of three classes of heterodimeric lipid kinases composed of a catalytic and regulatory subunit that, when activated, phosphorylate the $3^{\prime}$-hydroxyl group of phosphotidylinositols. The Class $\mathrm{I}_{\mathrm{A}} \mathrm{PI} 3 \mathrm{Ks}$ are the most well understood in terms of signal transduction and physiological relevance and are also the most widely implicated in the pathogenesis of breast and other cancers. Consequently, they are discussed at length in this review. The catalytic subunits that comprise Class $\mathrm{I}_{\mathrm{A}}$ PI3Ks are $\mathrm{p} 110 \mathrm{a}, \mathrm{p} 110 \beta, \mathrm{p} 110 \gamma$, and $\mathrm{p} 110 \delta$, which are encoded by the genes PIK3CA, PIK3CB, PIK3CG, and PIK3CD, respectively. In vitro, each p110 subunit has the capability of binding each of the regulatory subunits $-\mathrm{p} 85 \mathrm{a}$ (p85a, p55a, p50a), $\mathrm{p} 85 \beta$, and $555 \gamma$ - which are encoded by the genes PIK3R1, PIK3R2, and PIK3R3, respectively. For the sake of convention, the regulatory subunits are collectively referred to as p85 [6-11].

Activation of Class $\mathrm{I}_{\mathrm{A}}$ PI3Ks typically occurs through growth factor stimulation via receptor tyrosine kinases (RTKs), such as epidermal growth factor receptor (EGFR) and insulin-like growth factor-1 receptor (IGF-R1)[12-15]. However, other mechanisms such as signaling through G-protein-coupled receptors (GPCRs) and the small GTPase Ras have also been suggested to initiate PI3K activation [16-18]. In the case of RTKs, the Src homology 2 (SH2) domain of the p85 regulatory subunit binds a specific phosphotyrosine (pTyr) residue of the RTK, thus relieving the intermolecular inhibition of the p110 catalytic subunit and bringing it in close proximity to the lipid substrates in the membrane [19]. There the PI3K phosphorylates the $\mathrm{D} 3$ position on phosphoinositides to yield biologically active phosphatidylinositol-3,4,5-trisphosphate $\left(\mathrm{PI}(3,4,5) \mathrm{P}_{3}\right)$, which can then interact with lipid binding domains in PI3K effector proteins, changing their localization and/or activity [20, 4]. Conversely, PI3K is negatively regulated by the tumor suppressor, phosphatase and tensin homologue deleted on chromosome 10 (Pten), through the dephosphorylation of $\mathrm{PI}(3,4,5) \mathrm{P}_{3}$ back to its inactive lipid state [21].

After active PI3K generates PI(3,4,5) $\mathrm{P}_{3}$, the phosphotidylinositol recruits PDK-1 (3'phosphoinositide-dependent kinase 1) and the serine/threonine kinase Akt/PKB (protein kinase $\mathrm{B}$ ) via binding of their plextrin homology $(\mathrm{PH})$ domains to the plasma membrane where they are subsequently phosphorylated and activated [22]. This event is often viewed as the central node of the pathway since the activity of Akt is responsible for pleiotropic effects on molecular functions within the cell, such as cell cycle progression, apoptosis, transcription, and translation. There are three different yet structurally similar Akt isoforms (i.e. Akt1, Akt2, and Akt3) that are products of three distinct genes but share greater than $80 \%$ homology at the amino acid level [23]. Therefore, it is not surprising that each isoform is activated through very similar mechanisms: two crucial phosphorylation events involving homologous residues between the isoforms. For example, Akt1 is partially activated through an initial phosphorylation at threonine 308 by PDK- 1 and then fully activated by the subsequent phosphorylation at serine 473 by several potential kinases, such as PDK-1, integrin-linked kinase (ILK), DNA-dependent protein kinase (DNA-PK), mammalian target of rapamycin when bound to Rictor (mTORC2), or Akt itself [24-31]. This active form of Akt then translocates to either distinct areas within the cytosol or into the nucleus where it phosphorylates a host of downstream substrates, directly or indirectly, thereby mediating a multitude of effects. One of the major and most studied downstream effectors of Akt is the serine/threonine kinase mTOR (mammalian target of rapamycin), which is usually associated with other proteins in a complex known as mTORC1 [32]. Similar to the other aforementioned downstream substrates, Akt can activate mTOR indirectly through phosphorylation of Tsc2 (tuberous sclerosis complex 2). Tsc1 and Tsc2 are tumor 
suppressor proteins, thus the inhibited Tsc1/Tsc2 dimer allows the GTP-binding protein Rheb (Ras homolog enriched in brain) to remain in its active GTP-bound state, causing a rise in mTORC1 (mTOR in a protein complex with Raptor) activity [33, 34]. Down regulation of mTORC1 can occur under hypoxic and lower energy/ATP conditions through phosphorylation of the Tsc1/Tsc2 complex, on residues distinct from those phosphorylated by Akt, by REDD1 (regulated in development and DNA damage response 1) and AMPK (AMP-activated protein kinase), respectively [35, 36]. In the mTORC1 complex, mTOR phosphorylates p70S6K (70 kDa ribosomal protein S6 kinase) and 4E-BP1 (eIF4E-binding protein), leading directly to increased translation and synthesis of cell cycle regulating and ribosomal proteins $[37,38]$. The activation of p70S6K also serves a dual role of negative feedback to reduce the activation of the PI3K pathway through phosphorylation and subsequent inhibition of the adaptor molecule insulin receptor substrate 1 (IRS-1), which interrupts the signaling between the ligand-stimulated IGF-R1 and PI3K [39, 40].

\section{Activation of PI3K pathway in cancer}

As mentioned, the PI3K signaling pathway is aberrantly activated in numerous cancers, including breast cancers, with the two most commonly observed mechanisms of activation being RTK signaling via amplification/overexpression of Her2 and somatic mutations in specific components of the PI3K pathway [41, 42].

PI3K Activation in Breast Cancer Subtypes: Breast cancer subtypes are classified according to either gene expression profiles or immunohistochemistry staining, and each subtype reflects a different biology and clinical outcome. Immunohistochemical staining used to classify breast cancer subtypes currently includes ER, progesterone receptor (PR), Her2, and in some instances, the percentage of cells with Ki67 expression. Each breast cancer subtype can have varying and unique mechanisms of PI3K pathway alterations, resulting in potentially different clinical manifestations, necessitating the evolution of unique targeted therapeutic regimens. Thus, it has become paramount to identify and classify PI3K pathway aberrations according to breast cancer subtype, which is beyond the scope of this review, but has been extensively discussed in recent manuscripts elsewhere [43].

RTKs: PI3K is activated when the SH2 domain of the $\mathrm{p} 85$ regulatory subunit binds phosphotyrosine residues of activated RTKs or adaptor molecules; in breast cancer, overexpression, amplification, or mutation of an RTK can directly lead to constitutive activation of the PI3K pathway. Examples in human cancers include overexpression of fibroblast growth factor (FGF) and its corresponding receptor (FGFR), gain of function mutations of EGFR, and amplification of HER2 [44].

Somatic alterations: The phosphatase that is encoded by PTEN, which dephosphorylates $\mathrm{PI}(3,4,5) \mathrm{P}_{3}$ to $\mathrm{PI}(4,5) \mathrm{P}_{2}$, counters the action of $\mathrm{PI} 3 \mathrm{~K}$, and thus negatively regulates the pathway. Loss of Pten function has been documented in a variety of carcinomas through sporadic loss of function mutations, hetero- or homozygous deletion, and/or epigenetic silencing [45]. In addition, a congenital predisposition to breast cancer, known as Cowden's syndrome, is caused by germline mutations in PTEN [46]. While the aforementioned mutations are found at low frequencies within breast cancer, loss of heterozygosity affecting the PTEN locus, 10q23, occurs in roughly $30-40 \%$ of tumors $[47,48]$ and promoter hypermethylation occurs in approximately $50 \%$ of breast cancers $[49,50]$. This loss of Pten protein in tumors results in accumulation of $\mathrm{PI}(3,4,5) \mathrm{P}_{3}$ and, consequently, increased activation of Akt. Despite the frequency with which Pten function is abrogated in breast cancer, it remains unclear whether Pten loss by itself can activate the PI3K pathway and contribute to tumorigenesis. Indeed, recent studies have suggested that loss of Pten leads to activation of the PI3K pathway that is dependent upon p110 $\beta$ [51, 52]. Along these lines, 
some studies have reported that loss of Pten reduces the efficacy of RTK inhibitors as single agents [44], suggesting loss of Pten activates the PI3K pathway distal to RTK activation.

The PIK3CA gene, which encodes the p110a catalytic subunit of PI3K, is mutated at a high frequency in a number of human malignancies [3]. In breast cancers, PIK3CA has a reported overall mutation rate of $25 \%$, of which more than $80 \%$ reside in the "hot spot" regions within exon 9 of the helical domain and exon 20 of the catalytic domain [53]. These three mutations, E542K and E545K in exon 9 and H1047R in exon 20, confer increased PI3K catalytic activity, leading to cellular transformation through growth factor- and anchorageindependent cellular proliferation [54-56]. PIK3CA mutations commonly occur in ER (+) or HER 2 amplified breast tumors, and this has been speculated to be a major determinant of resistance to endocrine and Her2 targeted therapies, as will be discussed later [57].

The $A K T$ family of genes encodes three isoforms: Akt1, Akt2, and Akt3. To date, however, only the first two isoforms have documented alterations that contribute to breast carcinogenesis. For Akt1, within the lipid-binding PH domain, a somatic mutation resulting in a glutamic acid to lysine substitution at amino acid 17 (E17K) likely leads to transformation due to constitutive localization to the membrane, even in the absence of $\mathrm{PI}(3,4,5) \mathrm{P}_{3}$. This mutant, recently identified in $8 \%$ of breast cancers [58], is constitutively phosphorylated at S473 in the absence of serum but remains responsive to PI3K activation at T308, suggesting that this mutation alone may not be sufficient to drive tumorigenesis. Amplification and overexpression of Akt1 have also been noted albeit in a smaller subset of breast cancers. Conversely, amplification of the Akt2 gene has been detected in $4 \%$ of breast cancers while overexpression was found in 10-20\%, which corresponds to increased kinase activity in these tumors [59].

\title{
PI3K Pathway Inhibitors
}

\section{Rationale for targeting the PI3K pathway: oncogene addiction}

Typically, it is uncommon for cancer to arise from a single genetic abnormality. Rather, cancer is the cumulative effect of multiple genetic and epigenetic aberrations. But through a phenomenon known as "oncogene addiction," the cancer becomes dependent upon a particular alteration for survival as well as preservation of the malignant state. In theory, this dependency upon specific pathways, for instance the PI3K pathway in certain breast cancers, leaves the cancer vulnerable to potential pharmacological intervention that will selectively target the cancer cell while sparing normal tissue $[60,61]$. What follows are some of the genes in the PI3K pathway that are currently being targeted for breast cancer therapy.

\section{HER2}

\begin{abstract}
Aberrant cell signaling through the epidermal growth factor receptor family members has been associated with driving cancer cell growth. Because of their proximal position in signal transduction to both the MAPK and PI3K pathways, a review of targeting the PI3K pathway for breast cancer therapy would not be complete without some mention of this important class of RTKs. The most well-recognized and clinically relevant molecule with regard to breast cancer is the HER 2 oncogene. Amplification/overexpression of Her2 is present in approximately $25 \%$ of all breast cancers. This has translated into a remarkable success story with the introduction of trastuzumab, a humanized monoclonal antibody that has shown great success in the treatment of metastatic and early stage Her2 positive breast cancers [62]. Although various criteria have been developed to identify Her 2 positive breast cancers, including immunostaining and fluorescence in situ hybridization (FISH) analysis [63], it still appears that a significant proportion of patients with Her2 positive disease will have acquired or de novo resistance to trastuzumab. This has necessarily spurred further interest
\end{abstract}


in second generation Her2 directed therapies. The first of such therapies was the oral small molecule inhibitor lapatinib, a dual EGFR/Her2 kinase inhibitor. In metastatic patients, lapatinib with capecitabine demonstrated effectiveness with impressive response rates in trastuzumab refractory patients [64]. Results in early stage breast cancers using lapatinib with and without trastuzumab (Adjuvant Lapatinib and/or Trastuzumab Treatment Optimization (ALTTO)) have been completed and final results are expected soon, but initial results from a neoadjuvant study appears to demonstrate that dual Her2 inhibition with both lapatinib and trastuzumab may afford better outcomes (Neo ALTTO trial, San Antonio Breast Cancer Symposium, 2010). Similarly, in the metastatic setting, combining lapatinib with trastuzumab has been shown to be an effective non-chemotherapy containing regimen in women with Her2 positive disease [65].

Newer Her2 directed therapies are also in late stage development. TDM-1 is a cytotoxic agent linked to trastuzumab and in early clinical trials appears to have efficacy in trastuzumab refractory patients with very good tolerability. Another monoclonal antibody, pertuzumab, which inhibits the dimerization of Her2 to other EGFR family members has recently been reported in a Phase III trial to have impressive response rates when combined with trastuzumab and chemotherapy in metastatic disease (CLEOPATRA) [66]. Finally, due to the increased propensity of Her2 disease to metastasize to the central nervous system (CNS) and the inability of antibodies to effectively cross the blood-brain barrier, in theory making CNS metastases "sanctuary disease sites," there has been increased interest in studying the use of small molecule Her2 inhibitors (e.g. lapatinib) for the treatment of CNS disease. Neratinib, a small molecule EGFR/Her2 inhibitor similar to lapatinib is also currently being studied in Her2 metastatic disease with the hope that these Her2 directed small molecule inhibitors may afford better control of CNS metastatic disease.

\section{PI3K inhibitors - first generation}

Numerous PI3K pathway inhibitors have been developed, but the two earliest and most extensively explored are LY294002 and wortmannin. Despite effective inhibition of the PI3K pathway and demonstration of anti-tumor activity in breast cancer cell models, both have been limited to preclinical studies due to poor solubility, instability, and high toxicity [67, 68]. However, the backbone structures of LY294002 and wortmannin have served as templates for derivatives and prodrugs with better pharmacological properties. For instance, a vasculature-targeting Arg-Gly-Asp peptide was conjugated to LY294002 to form the prodrug SF-1126, a dual PI3K-mTOR inhibitor akin to the parent compound yet more stable and well tolerated, at least in murine models [69]. Similarly, the wortmannin analog PX-866 is a pan-PI3K inhibitor with increased cell permeability and a prolonged serum half-life [70]. Subsequent generations of pan-PI3K, dual PI3K-mTOR, isoform-specific PI3K, Akt, and mTOR inhibitors have been developed to circumvent the limitations of first generation compounds as well as unravel the complexity of the PI3K and alternative pathways through use of combination therapies [71].

\section{PI3K inhibitors - next generation}

Class-specific and isoform-specific PI3K inhibitors are attractive options since PI3K is the most proximal component of the pathway other than RTKs; therefore, targeting PI3K itself rather than Akt or mTOR could provide global inhibition of the downstream components within the pathway. This strategy, however, has potential for greater toxicity. Compounds selective for Class I PI3Ks currently in clinical development are GDC-0941 [72], XL-147 [73], BKM120 [74], GSK1059615As previously mentioned, several lines of evidence suggest that loss of Pten can lead to PI3K pathway activation, though recent data suggests that this may occur through activation of $\mathrm{p} 110 \beta$ activation [51, 52]. The exact mechanism of how this occurs remains to be elucidated, and indeed regulation of PTEN gene expression 
appears extraordinarily complex. Recent studies demonstrate the presence of a PTEN pseudogene within the human genome, showing an exquisitely balanced interplay between microRNAs (miRNAs) and PTEN/pseudogene mRNA, all contributing towards the tightly regulated expression of PTEN [91]. From a therapeutic standpoint, targeting the loss of a tumor suppressor gene has always been a challenging prospect. However, recent studies of a now classic "bench to bedside" drug development story suggested that the use of isogenic cell lines could identify molecules, poly(ADP-ribose) polymerase (PARP) inhibitors, that proved "synthetic lethal" for BRCA1 and BRCA2 null cells [92-94]. Somewhat surprisingly, one of these same groups recently reported using an identical approach that PARP inhibitors also imparted a synthetic lethal phenotype to cell lines with gene knock out of PTENbut not its isogenic controls [95]. Thus, although not historically thought of as a "druggable" target in the PI3K pathway, current research focusing on Pten loss for breast cancer therapy is ongoing.

\section{AKT}

Due to its central role in signal transduction and hyperactivation in many if not most human cancers, there has been intense research interests in developing Akt inhibitors as antineoplastic agents. Similar to the strategy for targeting PI3K in breast and other cancers, panisoform inhibitors have been developed, whereas synthesis of isoform-specific agents has proven difficult given the high degree of homology between the three Akt isoforms. There have been different strategies for developing Akt inhibitors, including ATP-competitive inhibitors, phosphotidylinositol analogs, and allosteric inhibitors. While pan-Akt, ATPcompetitive agents such as GSK690693 and A-443654 have demonstrated anti-tumor activity in preclinical models and are now in Phase I trials, allosteric inhibitors are also in various late stages of development and may have advantages in terms of selectivity and specificity $[96,97]$. These compounds interact with the PH domain or hinge region, promoting an inactive form of the enzyme by preventing localization to the membrane or access to the PDK-1-dependent phosphorylation site. MK-2206 is one such highly selective, allosteric pan-inhibitor that has entered Phase II clinical trials and shown marked suppression of breast cancer growth with acceptable tolerability [90, 98].

\section{mTOR}

Since its discovery in 1975, rapamycin has been extensively studied in relation to mTOR inhibition. The main proposed mechanism of action of rapamycin and its analogs is the formation of a complex with the FK506-binding protein (FKBP12) that can then bind the Cterminal region of mTOR, interfering with the kinase activity of the multimeric mTORC1 complex but not with mTORC2 [99]. However, similar to the situation with first generation PI3K inhibitors, rapamycin's undesirable pharmacological properties necessitated the derivation of more reliable analogs, colloquially known as "rapalogs." Three such rapalogs, RAD001 (everolimus), CCI-779 (temsirolimus), and AP-23573 (deferolimus) have shown cytostatic activity in preclinical models and anti-tumor activity when used in combination with chemotherapies [100]. More recently, the BOLERO-2 trial demonstrated that in metastatic breast cancer patients refractory to hormone therapies, the addition of everolimus to exemestane afforded improved progression free survival compared to women taking exemestane alone [101]. Despite the promise of these mTORC1 allosteric inhibitors, feedback activation of PI3K and Akt persists via mTORC2, potentially shifting the focus to ATP-competitive compounds that can inactivate both complexes and completely abrogate mTOR signaling. The first molecule of this class was PP242, and now its derivative, INK128, as well as several other pan-mTOR inhibitors such as AZD-8055 and OSI-027, are in early phase clinical trials for solid malignancies including breast cancers [32, 102]. 


\section{Combination therapies}

The PI3K pathway is extraordinarily complex and made more so due to the presence of multiple feedback loops and crosstalk with other signaling pathways [103]. The negative auto-regulation within the PI3K pathway and redundancy with the MAPK and LKB1/ AMPK pathways has likely evolved to ensure proper homeostatic control of cell growth in response to mitogenic signals and to prevent unwanted cell growth under specific cellular states, such as low energy conditions [104, 105]. The feedback inhibition leading to Akt activation could theoretically be overcome by alterations in any number of PI3K pathway nodal points as discussed above, which has also led to enthusiasm for the promise of small molecule inhibitors to antagonize such oncogenic events. But at the same time, the realization that compensatory alterations within either the PI3K or other redundant pathways can lead to acquired resistance to the therapy has tempered initial excitement. That said, a recurring tenant in clinical oncology is that increased efficacy is often demonstrated through the use of multiple agents, and in the case of PI3K-directed therapies, using additional PI3K pathway-specific compounds, targeted inhibitors in parallel and compensatory pathways, chemotherapies, or combinations thereof may afford the opportunity to surmount the vexing problem of drug resistance $[106,10]$.

As mentioned above, PIK3CA is the most frequently mutated component of the PI3K pathway in breast cancers, with over $80 \%$ of these mutations occurring in one of three hotspot residues, and the highest percentage found in the exon 20 hotspot mutation. Within the context of breast cancers, they are often associated with ER/PR expression, as well as HER2 overexpression, and are for the most part mutually exclusive with Pten loss [107] and $A K T 1$ mutations $[53,107]$. These mutations are thought to predict for response to other therapies targeting additional components of the PI3K pathways, e.g. PIK3CA mutations might be expected to predict for positive responses to mTOR inhibitors. In addition and as mentioned previously, PIK3CA mutations are felt to be negative predictors of response to molecules targeting proteins more proximal to PI3K, including Her2 directed therapies [83, $108,109,100,110]$ though data on this has not yet been fully validated in clinical trials. However, this provides the rationale for the potential use of Her2 directed therapies in combination with PI3K inhibitors, a testable hypothesis that is currently being addressed in a number of clinical trials.

Given the high incidence of PIK3CA mutations in ER/PR-positive breast cancers, along with evidence of non-genomic signaling of the MAPK pathway by ER signaling [111], it has been hypothesized that aberrant activation of the PI3K pathway may mediate resistance to endocrine therapies. Preclinical work and early phase trials support this notion. For example, a recent study demonstrated that estrogen deprivation in $\mathrm{ER}(+)$ breast tumors increased the apoptotic effects of the PI3K and dual-PI3K/mTOR inhibitors, BKM120 and BGT226 respectively [112]. The compounds were most effective when used in combination with fulvestrant, a selective estrogen receptor down-regulator (SERD). These results also concur with the recent findings of the BOLERO-2 trial as mentioned above.

However, activation of pathways due to PIK3CA mutations, and possibly Pten loss, appears to be more complex than originally thought. Though expected effects of Akt and mTOR activation have been reported using various in vitro models, several groups reported that MAPK pathway activation also surprisingly occurs when PIK3CA mutations are present and/or loss of PTEN $[55,56,113,114]$. Although others have previously demonstrated that mutant Ras can signal through p110a via its Ras Binding Domain (RBD) [115], the finding that mutant PIK3CA molecules can "reverse" this crosstalk was unexpected and indeed these mutations appear to function as more proximal mediators of signaling akin to RTK stimulation [116]. Recent reports suggest that HER3 and other molecules may mediate some of this complex process [117]. Thus, it may be that early clinical trials of PI3K inhibitors 
would not necessarily be expected to greatly impact breast cancers with PIK3CA mutations and/or Pten loss. Based on the emerging complexity and "rewiring" of pathways imparted by PIK3CA mutations and Pten loss, dual RTK/PI3K and PI3K/MAPK pathway inhibitors are currently being evaluated as combination therapies in early phase trials to rationally target these two key growth promoting pathways. As might be expected, increased toxicity has been seen in some of these early trials, necessitating careful evaluation as these trials continue to move forward.

\section{Need for Clinical Biomarkers}

\section{Patient selection \& biomarkers}

Currently in clinical oncology drug development, targeted therapies rely upon the establishment of companion diagnostics that are reproducible and robust, such that they will have a high likelihood of predicting response to a given therapy. Notable examples in breast cancer therapy include the presence of ER/PR for endocrine therapies, as well as methods for assessing Her2 overexpression/amplification by immunohistochemistry and FISH, for predicting response to Her2 directed therapies such as trastuzumab and lapatinib. More recent examples of breast cancer biomarkers include those cancers with loss of BRCA1 or BRCA2 predicting for response to PARP inhibitors [94]. Finally, the establishment of Oncotype DX as a predictive assay, apart from its utility as a prognostic test, affords the ability to estimate the likelihood of chemotherapy benefit for a given patient [118]. Although chemotherapy is not considered a targeted therapy for breast cancer, this last example highlights the unmet need in establishing predictive assays to choose patients who will have the highest likelihood of benefit, thus sparing needless toxicity and costs to patients and society.

For PI3K pathway inhibitors, there has been intense interest in developing companion diagnostics for the reasons mentioned above. How reliably a given test performs will depend on a number of factors, including both biological and technical challenges. Using the above examples, PIK3CA mutations, Pten loss and $A K T 1$ (E17K) mutations might be logical choices as positive predictors of response to PI3K, Akt and mTOR inhibitors. To date, however, no single study has demonstrated that any of these genetic alterations have strong predictive abilities. In the case of PIK3CA mutations and Pten loss, this may be due to the activation of other pathways as previously mentioned, suggesting that drugs targeting additional pathways may be needed. Interestingly, the E17K Akt1 mutation demonstrated no obvious phenotype when introduced as a somatic mutation into breast epithelial cells via gene targeting [119]. The reasons for this are unknown but could include effects of single versus multiple copy numbers of the E17K allele, cell-specific context of the mutation, additional unknown but requisite mutations in cooperating genes, etc. However, suffice it to say that the mutation itself will not necessarily predict for pathway activation nor, consequently, for response to targeted therapies. Intriguingly, the Braf V600E mutation, which is both the target and a predictive marker of response for the small molecule inhibitor vemurafenib, was found to be highly active in metastatic melanomas harboring the mutation [120] but not in colorectal cancers with mutant Braf V600E. This has recently been shown to be due to the presence of EGFR in experimental models, which modulates the activity of the mutant Braf protein [121]. This example highlights that finding predictive markers of response to targeted therapeutics in breast cancer using somatic mutations such as PIK3CA may not be applicable for other tumor types and vice versa.

Of concern for the use of PIK $3 C A$ mutation status as positive predictors of response to $\mathrm{PI} 3 \mathrm{~K}$-targeted therapies is the growing realization that tumor heterogeneity may make the use of somatic alterations problematic. Similar to recent data suggesting ER and Her2 status can change in metastatic lesions $[122,123]$, reports have also emerged suggesting that 
PIK3CA mutational status in breast cancer patients is prone to discordance when comparing primary versus metastatic lesions $[124,125]$. As most trials heretofore have used archival tissue specimens to assess mutation status, current thinking suggests that this may not truly reflect the status of disease at the time of consideration for directed targeted therapies. As such, biopsy of metastatic lesions is becoming more common place for breast and other cancers. However, the inability to obtain biopsies from metastatic sites presents a conundrum for many patients and potentially limits the utility of future PI $3 \mathrm{~K}$ targeted therapies. Therefore, attempts to evaluate disease and predictors of response in a noninvasive manner have gained much interest and attention.

Ideally, a non-invasive functional test would offer great utility as a predictive assay for PI3K-directed therapies in breast cancer. Because hyperactivation of the PI3K pathway predictably leads to increases in glucose metabolism, there has been great enthusiasm for researching the utility of [18F] fluorodeoxyglucose (FDG)-positron emission tomography (PET) to not only evaluate disease burden but to simultaneously assess whether FDG-PET scanning can offer predictive value for PI3K pathway inhibitors. In theory this idea seems plausible, as any perturbation of the PI3K pathway, whether genetic, epigenetic, or otherwise would lead to a functional state of increased glucose metabolism that should correlate with response to therapy. This approach, however, may have a "fatal flaw" in that not knowing where the "lesion" is could prevent efficacy and reduce the perceived predictive power. For example, hyperactivation of the PI3K pathway by Pten loss may lead to a positive result by FDG-PET scans, but an isoform specific p110a inhibitor would likely not be effective in such a tumor. Thus, FDG-PET may be useful as an adjunct test for functional analysis of the pathway in addition to evaluation of the genetic lesion that accounts for pathway activation.

Newer technologies in development offer the potential for mutation detection from blood. As example, recent studies have shown the utility of detecting PIK3CA mutations using blood from breast cancer patients [126]. However, for such a test to be clinical meaningful, sensitivity and specificity must be greatly increased beyond traditional sequencing methods and PCR assays. BEAMing $[127,128]$ is a novel technique based upon digital, emulsionbased PCR with mutation detection. This technology has been shown to reliably detect rare mutant alleles found in the blood of colorectal cancer patients [129, 130]. More recently, retrospective and prospective studies have also demonstrated the feasibility and utility of BEAMing for evaluating the PIK3CA mutation status of breast cancer patients (manuscript in revision). Similar to other studies, however, discordance between primary and metastatic lesions was present again, suggesting that assessing mutation status at the time of targeted therapy would likely afford the best chance of predicting response. Future work with targeted therapies against the PI3K pathway in breast cancer will almost certainly incorporate additional novel assays such that targeted therapies truly are given to the proper patients.

\section{Conclusions}

Breast cancer therapy has undergone a remarkable revolution in the past two decades with the advent of truly targeted therapies with remarkable efficacy and tolerable toxicities. Indeed, the successes of endocrine therapies for ER/PR positive disease and trastuzumab therapies for Her2-positive disease have not only shed new insights into the molecular underpinnings driving subtypes of breast cancer, but have also provided a glimpse into how drug resistance to these therapies can emerge. This history of success coupled with current knowledge and understanding of breast cancer due to gene expression profiling, mutational analysis, copy number changes and genomic rearrangements have led to a strong impetus and optimism that future targeted therapies will continue to greatly decrease breast cancer 
mortality with minimal side effects. Targeting the PI3K pathway in particular, along with cutting edge companion diagnostic predictors of response, engenders great enthusiasm that future therapies for breast cancer will truly be curative for all types and stages of breast cancer.

\section{REFERENCES}

1. Sugimoto Y, Whitman M, Cantley LC, Erikson RL. Evidence that the Rous sarcoma virus transforming gene product phosphorylates phosphatidylinositol and diacylglycerol. Proc Natl Acad Sci U S A. 1984; 81(7):2117-21. [PubMed: 6326105]

2. Engelman JA, Luo J, Cantley LC. The evolution of phosphatidylinositol 3-kinases as regulators of growth and metabolism. Nat Rev Genet. 2006; 7(8):606-19. [PubMed: 16847462]

3. Samuels Y, Wang Z, Bardelli A, Silliman N, Ptak J, Szabo S, et al. High frequency of mutations of the PIK3CA gene in human cancers. Science. 2004; 304(5670):554. [PubMed: 15016963]

4. Whitman M, Kaplan DR, Schaffhausen B, Cantley L, Roberts TM. Association of phosphatidylinositol kinase activity with polyoma middle-T competent for transformation. Nature. 1985; 315(6016):239-42. [PubMed: 2987699]

5. Gustin JP, Cosgrove DP, Park BH. The PIK3CA gene as a mutated target for cancer therapy. Curr Cancer Drug Targets. 2008; 8(8):733-40. [PubMed: 19075596]

6. Vanhaesebroeck B, Guillermet-Guibert J, Graupera M, Bilanges B. The emerging mechanisms of isoform-specific PI3K signalling. Nat Rev Mol Cell Biol. 2010; 11(5):329-41. [PubMed: 20379207]

7. Courtney KD, Corcoran RB, Engelman JA. The PI3K pathway as drug target in human cancer. J Clin Oncol. 2010; 28(6):1075-83. [PubMed: 20085938]

8. Engelman JA. Targeting PI3K signalling in cancer: opportunities, challenges and limitations. Nat Rev Cancer. 2009; 9(8):550-62. [PubMed: 19629070]

9. Yap TA, Garrett MD, Walton MI, Raynaud F, de Bono JS, Workman P. Targeting the PI3K-AKTmTOR pathway: progress, pitfalls, and promises. Curr Opin Pharmacol. 2008; 8(4):393-412. [PubMed: 18721898]

10. LoPiccolo J, Blumenthal GM, Bernstein WB, Dennis PA. Targeting the PI3K/Akt/mTOR pathway: effective combinations and clinical considerations. Drug Resist Updat. 2008; 11(1-2):32-50. [PubMed: 18166498]

11. Katso R, Okkenhaug K, Ahmadi K, White S, Timms J, Waterfield MD. Cellular function of phosphoinositide 3-kinases: implications for development, homeostasis, and cancer. Annu Rev Cell Dev Biol. 2001; 17:615-75. [PubMed: 11687500]

12. Escobedo JA, Navankasattusas S, Kavanaugh WM, Milfay D, Fried VA, Williams LT. cDNA cloning of a novel $85 \mathrm{kd}$ protein that has $\mathrm{SH} 2$ domains and regulates binding of PI3-kinase to the PDGF beta-receptor. Cell. 1991; 65(1):75-82. [PubMed: 1849460]

13. Otsu M, Hiles I, Gout I, Fry MJ, Ruiz-Larrea F, Panayotou G, et al. Characterization of two 85 kd proteins that associate with receptor tyrosine kinases, middle-T/pp60c-src complexes, and PI3kinase. Cell. 1991; 65(1):91-104. [PubMed: 1707345]

14. Skolnik EY, Margolis B, Mohammadi M, Lowenstein E, Fischer R, Drepps A, et al. Cloning of PI3 kinase-associated p85 utilizing a novel method for expression/cloning of target proteins for receptor tyrosine kinases. Cell. 1991; 65(1):83-90. [PubMed: 1849461]

15. Myers MG Jr. Backer JM, Sun XJ, Shoelson S, Hu P, Schlessinger J, et al. IRS-1 activates phosphatidylinositol $3^{\prime}$-kinase by associating with src homology 2 domains of p85. Proc Natl Acad Sci U S A. 1992; 89(21):10350-4. [PubMed: 1332046]

16. Guillermet-Guibert J, Bjorklof K, Salpekar A, Gonella C, Ramadani F, Bilancio A, et al. The p110beta isoform of phosphoinositide 3-kinase signals downstream of $\mathrm{G}$ protein-coupled receptors and is functionally redundant with p110gamma. Proc Natl Acad Sci U S A. 2008; 105(24):8292-7. [PubMed: 18544649]

17. Stoyanov B, Volinia S, Hanck T, Rubio I, Loubtchenkov M, Malek D, et al. Cloning and characterization of a $\mathrm{G}$ protein-activated human phosphoinositide-3 kinase. Science. 1995; 269(5224):690-3. [PubMed: 7624799] 
18. Shaw RJ, Cantley LC. Ras, PI(3)K and mTOR signalling controls tumour cell growth. Nature. 2006; 441(7092):424-30. [PubMed: 16724053]

19. Carpenter CL, Auger KR, Chanudhuri M, Yoakim M, Schaffhausen B, Shoelson S, et al. Phosphoinositide 3-kinase is activated by phosphopeptides that bind to the $\mathrm{SH} 2$ domains of the 85kDa subunit. J Biol Chem. 1993; 268(13):9478-83. [PubMed: 7683653]

20. Whitman M, Downes CP, Keeler M, Keller T, Cantley L. Type I phosphatidylinositol kinase makes a novel inositol phospholipid, phosphatidylinositol-3-phosphate. Nature. 1988; 332(6165): 644-6. [PubMed: 2833705]

21. Maehama T, Dixon JE. The tumor suppressor, PTEN/MMAC1, dephosphorylates the lipid second messenger, phosphatidylinositol 3,4,5-trisphosphate. J Biol Chem. 1998; 273(22):13375-8. [PubMed: 9593664]

22. Burgering BM, Coffer PJ. Protein kinase B (c-Akt) in phosphatidylinositol-3-OH kinase signal transduction. Nature. 1995; 376(6541):599-602. [PubMed: 7637810]

23. Nicholson KM, Anderson NG. The protein kinase B/Akt signalling pathway in human malignancy. Cell Signal. 2002; 14(5):381-95. [PubMed: 11882383]

24. Alessi DR, Andjelkovic M, Caudwell B, Cron P, Morrice N, Cohen P, et al. Mechanism of activation of protein kinase B by insulin and IGF-1. Embo J. 1996; 15(23):6541-51. [PubMed: 8978681]

25. Balendran A, Casamayor A, Deak M, Paterson A, Gaffney P, Currie R, et al. PDK1 acquires PDK2 activity in the presence of a synthetic peptide derived from the carboxyl terminus of PRK2. Curr Biol. 1999; 9(8):393-404. [PubMed: 10226025]

26. Feng J, Park J, Cron P, Hess D, Hemmings BA. Identification of a PKB/Akt hydrophobic motif Ser-473 kinase as DNA-dependent protein kinase. J Biol Chem. 2004; 279(39):41189-96. [PubMed: 15262962]

27. Hresko RC, Mueckler M. mTOR.RICTOR is the Ser473 kinase for Akt/protein kinase B in 3T3-L1 adipocytes. J Biol Chem. 2005; 280(49):40406-16. [PubMed: 16221682]

28. Lynch DK, Ellis CA, Edwards PA, Hiles ID. Integrin-linked kinase regulates phosphorylation of serine 473 of protein kinase B by an indirect mechanism. Oncogene. 1999; 18(56):8024-32. [PubMed: 10637513]

29. Sarbassov DD, Ali SM, Sengupta S, Sheen JH, Hsu PP, Bagley AF, et al. Prolonged rapamycin treatment inhibits mTORC2 assembly and Akt/PKB. Mol Cell. 2006; 22(2):159-68. [PubMed: 16603397]

30. Sarbassov DD, Guertin DA, Ali SM, Sabatini DM. Phosphorylation and regulation of Akt/PKB by the rictor-mTOR complex. Science. 2005; 307(5712):1098-101. [PubMed: 15718470]

31. Toker A, Newton AC. Akt/protein kinase B is regulated by autophosphorylation at the hypothetical PDK-2 site. J Biol Chem. 2000; 275(12):8271-4. [PubMed: 10722653]

32. Benjamin D, Colombi M, Moroni C, Hall MN. Rapamycin passes the torch: a new generation of mTOR inhibitors. Nat Rev Drug Discov. 2011; 10(11):868-80. [PubMed: 22037041]

33. Castro AF, Rebhun JF, Clark GJ, Quilliam LA. Rheb binds tuberous sclerosis complex 2 (TSC2) and promotes $\mathrm{S} 6$ kinase activation in a rapamycin- and farnesylation-dependent manner. J Biol Chem. 2003; 278(35):32493-6. [PubMed: 12842888]

34. Inoki K, Li Y, Zhu T, Wu J, Guan KL. TSC2 is phosphorylated and inhibited by Akt and suppresses mTOR signalling. Nat Cell Biol. 2002; 4(9):648-57. [PubMed: 12172553]

35. Brugarolas J, Lei K, Hurley RL, Manning BD, Reiling JH, Hafen E, et al. Regulation of mTOR function in response to hypoxia by REDD1 and the TSC1/TSC2 tumor suppressor complex. Genes Dev. 2004; 18(23):2893-904. [PubMed: 15545625]

36. Inoki K, Zhu T, Guan KL. TSC2 mediates cellular energy response to control cell growth and survival. Cell. 2003; 115(5):577-90. [PubMed: 14651849]

37. Beretta L, Gingras AC, Svitkin YV, Hall MN, Sonenberg N. Rapamycin blocks the phosphorylation of 4E-BP1 and inhibits cap-dependent initiation of translation. Embo J. 1996; 15(3):658-64. [PubMed: 8599949]

38. Chung J, Kuo CJ, Crabtree GR, Blenis J. Rapamycin-FKBP specifically blocks growth-dependent activation of and signaling by the 70 kd S6 protein kinases. Cell. 1992; 69(7):1227-36. [PubMed: 1377606] 
39. Harrington LS, Findlay GM, Gray A, Tolkacheva T, Wigfield S, Rebholz H, et al. The TSC1-2 tumor suppressor controls insulin-PI3K signaling via regulation of IRS proteins. J Cell Biol. 2004; 166(2):213-23. [PubMed: 15249583]

40. Shah OJ, Wang Z, Hunter T. Inappropriate activation of the TSC/Rheb/mTOR/S6K cassette induces IRS1/2 depletion, insulin resistance, and cell survival deficiencies. Curr Biol. 2004; 14(18):1650-6. [PubMed: 15380067]

41. Baselga J. Targeting the phosphoinositide-3 (PI3) kinase pathway in breast cancer. Oncologist. 2011; 16(Suppl 1):12-9. [PubMed: 21278436]

42. Yuan TL, Cantley LC. PI3K pathway alterations in cancer: variations on a theme. Oncogene. 2008; 27(41):5497-510. [PubMed: 18794884]

43. Boyault S, Drouet Y, Navarro C, Bachelot T, Lasset C, Treilleux I, et al. Mutational characterization of individual breast tumors: TP53 and PI3K pathway genes are frequently and distinctively mutated in different subtypes. Breast Cancer Res Treat. 2012

44. Ghayad SE, Cohen PA. Inhibitors of the PI3K/Akt/mTOR pathway: new hope for breast cancer patients. Recent Pat Anticancer Drug Discov. 2010; 5(1):29-57. [PubMed: 19751211]

45. Sansal I, Sellers WR. The biology and clinical relevance of the PTEN tumor suppressor pathway. J Clin Oncol. 2004; 22(14):2954-63. [PubMed: 15254063]

46. Liaw D, Marsh DJ, Li J, Dahia PL, Wang SI, Zheng Z, et al. Germline mutations of the PTEN gene in Cowden disease, an inherited breast and thyroid cancer syndrome. Nat Genet. 1997; 16(1):64-7. [PubMed: 9140396]

47. Singh B, Ittmann MM, Krolewski JJ. Sporadic breast cancers exhibit loss of heterozygosity on chromosome segment 10q23 close to the Cowden disease locus. Genes Chromosomes Cancer. 1998; 21(2):166-71. [PubMed: 9491329]

48. Garcia JM, Silva JM, Dominguez G, Gonzalez R, Navarro A, Carretero L, et al. Allelic loss of the PTEN region (10q23) in breast carcinomas of poor pathophenotype. Breast Cancer Res Treat. 1999; 57(3):237-43. [PubMed: 10617300]

49. Garcia JM, Silva J, Pena C, Garcia V, Rodriguez R, Cruz MA, et al. Promoter methylation of the PTEN gene is a common molecular change in breast cancer. Genes Chromosomes Cancer. 2004; 41(2):117-24. [PubMed: 15287024]

50. Khan S, Kumagai T, Vora J, Bose N, Sehgal I, Koeffler PH, et al. PTEN promoter is methylated in a proportion of invasive breast cancers. Int J Cancer. 2004; 112(3):407-10. [PubMed: 15382065]

51. Wee S, Wiederschain D, Maira SM, Loo A, Miller C, deBeaumont R, et al. PTEN-deficient cancers depend on PIK3CB. Proc Natl Acad Sci U S A. 2008; 105(35):13057-62. [PubMed: 18755892]

52. Jia S, Liu Z, Zhang S, Liu P, Zhang L, Lee SH, et al. Essential roles of PI(3)K-p110beta in cell growth, metabolism and tumorigenesis. Nature. 2008; 454(7205):776-9. [PubMed: 18594509]

53. Bachman KE, Argani P, Samuels Y, Silliman N, Ptak J, Szabo S, et al. The PIK3CA gene is mutated with high frequency in human breast cancers. Cancer Biol Ther. 2004; 3(8):772-5. [PubMed: 15254419]

54. Campbell IG, Russell SE, Choong DY, Montgomery KG, Ciavarella ML, Hooi CS, et al. Mutation of the PIK3CA gene in ovarian and breast cancer. Cancer Res. 2004; 64(21):7678-81. [PubMed: 15520168]

55. Gustin JP, Karakas B, Weiss MB, Abukhdeir AM, Lauring J, Garay JP, et al. Knockin of mutant PIK3CA activates multiple oncogenic pathways. Proc Natl Acad Sci U S A. 2009; 106(8):283540. [PubMed: 19196980]

56. Isakoff SJ, Engelman JA, Irie HY, Luo J, Brachmann SM, Pearline RV, et al. Breast cancerassociated PIK3CA mutations are oncogenic in mammary epithelial cells. Cancer Res. 2005; 65(23):10992-1000. [PubMed: 16322248]

57. Miller TW, Balko JM, Arteaga CL. Phosphatidylinositol 3-Kinase and Antiestrogen Resistance in Breast Cancer. J Clin Oncol. 2011

58. Carpten JD, Faber AL, Horn C, Donoho GP, Briggs SL, Robbins CM, et al. A transforming mutation in the pleckstrin homology domain of AKT1 in cancer. Nature. 2007; 448(7152):439-44. [PubMed: 17611497] 
59. Sun M, Paciga JE, Feldman RI, Yuan Z, Coppola D, Lu YY, et al. Phosphatidylinositol-3-OH Kinase (PI3K)/AKT2, activated in breast cancer, regulates and is induced by estrogen receptor alpha (ERalpha) via interaction between ERalpha and PI3K. Cancer Res. 2001; 61(16):5985-91. [PubMed: 11507039]

60. Luo J, Manning BD, Cantley LC. Targeting the PI3K-Akt pathway in human cancer: rationale and promise. Cancer Cell. 2003; 4(4):257-62. [PubMed: 14585353]

61. Weinstein IB. Cancer. Addiction to oncogenes--the Achilles heal of cancer. Science. 2002; 297(5578):63-4. [PubMed: 12098689]

62. Pegram MD, Konecny G, Slamon DJ. The molecular and cellular biology of HER2/neu gene amplification/overexpression and the clinical development of herceptin (trastuzumab) therapy for breast cancer. Cancer Treat Res. 2000; 103:57-75. [PubMed: 10948442]

63. Sauter G, Lee J, Bartlett JM, Slamon DJ, Press MF. Guidelines for human epidermal growth factor receptor 2 testing: biologic and methodologic considerations. J Clin Oncol. 2009; 27(8):1323-33. [PubMed: 19204209]

64. Geyer CE, Forster J, Lindquist D, Chan S, Romieu CG, Pienkowski T, et al. Lapatinib plus capecitabine for HER2-positive advanced breast cancer. N Engl J Med. 2006; 355(26):2733-43. [PubMed: 17192538]

65. Blackwell KL, Burstein HJ, Storniolo AM, Rugo H, Sledge G, Koehler M, et al. Randomized study of Lapatinib alone or in combination with trastuzumab in women with ErbB2-positive, trastuzumab-refractory metastatic breast cancer. J Clin Oncol. 2010; 28(7):1124-30. [PubMed: 20124187]

66. Baselga J, Cortes J, Kim SB, Im SA, Hegg R, Im YH, et al. Pertuzumab plus Trastuzumab plus Docetaxel for Metastatic Breast Cancer. N Engl J Med. 2011

67. Arcaro A, Wymann MP. Wortmannin is a potent phosphatidylinositol 3-kinase inhibitor: the role of phosphatidylinositol 3,4,5-trisphosphate in neutrophil responses. Biochem J. 1993; 296(Pt 2): 297-301. [PubMed: 8257416]

68. Vlahos CJ, Matter WF, Hui KY, Brown RF. A specific inhibitor of phosphatidylinositol 3-kinase, 2-(4-morpholinyl)-8-phenyl-4H-1-benzopyran-4-one (LY294002). J Biol Chem. 1994; 269(7): 5241-8. [PubMed: 8106507]

69. Garlich JR, De P, Dey N, Su JD, Peng X, Miller A, et al. A vascular targeted pan phosphoinositide 3-kinase inhibitor prodrug, SF1126, with antitumor and antiangiogenic activity. Cancer Res. 2008; 68(1):206-15. [PubMed: 18172313]

70. Ihle NT, Williams R, Chow S, Chew W, Berggren MI, Paine-Murrieta G, et al. Molecular pharmacology and antitumor activity of PX-866, a novel inhibitor of phosphoinositide-3-kinase signaling. Mol Cancer Ther. 2004; 3(7):763-72. [PubMed: 15252137]

71. Garcia-Echeverria C, Sellers WR. Drug discovery approaches targeting the PI3K/Akt pathway in cancer. Oncogene. 2008; 27(41):5511-26. [PubMed: 18794885]

72. O’Brien C, Wallin JJ, Sampath D, GuhaThakurta D, Savage H, Punnoose EA, et al. Predictive biomarkers of sensitivity to the phosphatidylinositol 3' kinase inhibitor GDC-0941 in breast cancer preclinical models. Clin Cancer Res. 2010; 16(14):3670-83. [PubMed: 20453058]

73. Chakrabarty A, Sanchez V, Kuba MG, Rinehart C, Arteaga CL. Feedback upregulation of HER3 (ErbB3) expression and activity attenuates antitumor effect of PI3K inhibitors. Proc Natl Acad Sci U S A. 2012; 109(8):2718-23. [PubMed: 21368164]

74. Maira SM, Pecchi S, Huang A, Burger M, Knapp M, Sterker D, et al. Identification and characterization of NVP-BKM120, an orally available pan class I PI3-Kinase inhibitor. Mol Cancer Ther. 2012

75. Castillo JJ, Furman M, Winer ES. CAL-101: a phosphatidylinositol-3-kinase p110-delta inhibitor for the treatment of lymphoid malignancies. Expert Opin Investig Drugs. 2012; 21(1):15-22.

76. Howes AL, Chiang GG, Lang ES, Ho CB, Powis G, Vuori K, et al. The phosphatidylinositol 3 kinase inhibitor, PX-866, is a potent inhibitor of cancer cell motility and growth in threedimensional cultures. Mol Cancer Ther. 2007; 6(9):2505-14. [PubMed: 17766839]

77. Lin H, Erhard K, Hardwicke MA, Luengo JI, Mack JF, McSurdy-Freed J, et al. Synthesis and structure-activity relationships of imidazo[1,2-a]pyrimidin-5(1H)-ones as a novel series of beta isoform selective phosphatidylinositol 3-kinase inhibitors. Bioorg Med Chem Lett. 2012 
78. Guerreiro AS, Fattet S, Kulesza DW, Atamer A, Elsing AN, Shalaby T, et al. A sensitized RNA interference screen identifies a novel role for the PI3K p110gamma isoform in medulloblastoma cell proliferation and chemoresistance. Mol Cancer Res. 2011; 9(7):925-35. [PubMed: 21652733]

79. Tanaka H, Yoshida M, Tanimura H, Fujii T, Sakata K, Tachibana Y, et al. The selective class I PI3K inhibitor CH5132799 targets human cancers harboring oncogenic PIK3CA mutations. Clin Cancer Res. 2011; 17(10):3272-81. [PubMed: 21558396]

80. Vasudevan KM, Barbie DA, Davies MA, Rabinovsky R, McNear CJ, Kim JJ, et al. AKTindependent signaling downstream of oncogenic PIK3CA mutations in human cancer. Cancer Cell. 2009; 16(1):21-32. [PubMed: 19573809]

81. Carvalho S, Milanezi F, Costa JL, Amendoeira I, Schmitt F. PIKing the right isoform: the emergent role of the p110beta subunit in breast cancer. Virchows Arch. 2010; 456(3):235-43. [PubMed: 20130907]

82. Crowder RJ, Phommaly C, Tao Y, Hoog J, Luo J, Perou CM, et al. PIK3CA and PIK3CB inhibition produce synthetic lethality when combined with estrogen deprivation in estrogen receptor-positive breast cancer. Cancer Res. 2009; 69(9):3955-62. [PubMed: 19366795]

83. Brachmann SM, Hofmann I, Schnell C, Fritsch C, Wee S, Lane H, et al. Specific apoptosis induction by the dual PI3K/mTor inhibitor NVP-BEZ235 in HER2 amplified and PIK3CA mutant breast cancer cells. Proc Natl Acad Sci U S A. 2009; 106(52):22299-304. [PubMed: 20007781]

84. Markman B, Tabernero J, Krop I, Shapiro GI, Siu L, Chen LC, et al. Phase I safety, pharmacokinetic, and pharmacodynamic study of the oral phosphatidylinositol-3-kinase and mTOR inhibitor BGT226 in patients with advanced solid tumors. Ann Oncol. 2012

85. Mallon R, Feldberg LR, Lucas J, Chaudhary I, Dehnhardt C, Santos ED, et al. Antitumor efficacy of PKI-587, a highly potent dual PI3K/mTOR kinase inhibitor. Clin Cancer Res. 2011; 17(10): 3193-203. [PubMed: 21325073]

86. Mallon R, Hollander I, Feldberg L, Lucas J, Soloveva V, Venkatesan A, et al. Antitumor efficacy profile of PKI-402, a dual phosphatidylinositol 3-kinase/mammalian target of rapamycin inhibitor. Mol Cancer Ther. 2010; 9(4):976-84. [PubMed: 20371716]

87. Mirzoeva OK, Hann B, Hom YK, Debnath J, Aftab D, Shokat K, et al. Autophagy suppression promotes apoptotic cell death in response to inhibition of the PI3K-mTOR pathway in pancreatic adenocarcinoma. J Mol Med (Berl). 2011; 89(9):877-89. [PubMed: 21678117]

88. Ozbay T, Durden DL, Liu T, O’Regan RM, Nahta R. In vitro evaluation of pan-PI3-kinase inhibitor SF1126 in trastuzumab-sensitive and trastuzumab-resistant HER2-over-expressing breast cancer cells. Cancer Chemother Pharmacol. 2010; 65(4):697-706. [PubMed: 19636556]

89. Wallin JJ, Edgar KA, Guan J, Berry M, Prior WW, Lee L, et al. GDC-0980 Is a Novel Class I PI3K/mTOR Kinase Inhibitor with Robust Activity in Cancer Models Driven by the PI3K Pathway. Mol Cancer Ther. 2011; 10(12):2426-36. [PubMed: 21998291]

90. Hernandez-Aya LF, Gonzalez-Angulo AM. Targeting the phosphatidylinositol 3-kinase signaling pathway in breast cancer. Oncologist. 2011; 16(4):404-14. [PubMed: 21406469]

91. Poliseno L, Salmena L, Zhang J, Carver B, Haveman WJ, Pandolfi PP. A coding-independent function of gene and pseudogene mRNAs regulates tumour biology. Nature. 2010; 465(7301): 1033-8. [PubMed: 20577206]

92. Bryant HE, Schultz N, Thomas HD, Parker KM, Flower D, Lopez E, et al. Specific killing of BRCA2-deficient tumours with inhibitors of poly(ADP-ribose) polymerase. Nature. 2005; 434(7035):913-7. [PubMed: 15829966]

93. Farmer H, McCabe N, Lord CJ, Tutt AN, Johnson DA, Richardson TB, et al. Targeting the DNA repair defect in BRCA mutant cells as a therapeutic strategy. Nature. 2005; 434(7035):917-21. [PubMed: 15829967]

94. Fong PC, Boss DS, Yap TA, Tutt A, Wu P, Mergui-Roelvink M, et al. Inhibition of poly(ADPribose) polymerase in tumors from BRCA mutation carriers. N Engl J Med. 2009; 361(2):123-34. [PubMed: 19553641]

95. Mendes-Pereira AM, Martin SA, Brough R, McCarthy A, Taylor JR, Kim JS, et al. Synthetic lethal targeting of PTEN mutant cells with PARP inhibitors. EMBO Mol Med. 2009; 1(6-7):315-22. [PubMed: 20049735] 
96. Carol H, Morton CL, Gorlick R, Kolb EA, Keir ST, Reynolds CP, et al. Initial testing (stage 1) of the Akt inhibitor GSK690693 by the pediatric preclinical testing program. Pediatr Blood Cancer. 2010; 55(7):1329-37. [PubMed: 20740623]

97. Chan TO, Zhang J, Rodeck U, Pascal JM, Armen RS, Spring M, et al. Resistance of Akt kinases to dephosphorylation through ATP-dependent conformational plasticity. Proc Natl Acad Sci U S A. 2011; 108(46):E1120-7. [PubMed: 22031698]

98. Yap TA, Yan L, Patnaik A, Fearen I, Olmos D, Papadopoulos K, et al. First-in-man clinical trial of the oral pan-AKT inhibitor MK-2206 in patients with advanced solid tumors. J Clin Oncol. 2011; 29(35):4688-95. [PubMed: 22025163]

99. Wiederrecht GJ, Sabers CJ, Brunn GJ, Martin MM, Dumont FJ, Abraham RT. Mechanism of action of rapamycin: new insights into the regulation of G1-phase progression in eukaryotic cells. Prog Cell Cycle Res. 1995; 1:53-71. [PubMed: 9552353]

100. Miller TW, Rexer BN, Garrett JT, Arteaga CL. Mutations in the phosphatidylinositol 3-kinase pathway: role in tumor progression and therapeutic implications in breast cancer. Breast Cancer Res. 2011; 13(6):224. [PubMed: 22114931]

101. Baselga J, Campone M, Piccart M, Burris HA, Rugo HS, Sahmoud T, et al. Everolimus in Postmenopausal Hormone-Receptor-Positive Advanced Breast Cancer. N Engl J Med. 2011

102. O'Regan R, Hawk NN. mTOR inhibition in breast cancer: unraveling the complex mechanisms of mTOR signal transduction and its clinical implications in therapy. Expert Opin Ther Targets. 2011; 15(7):859-72. [PubMed: 21476875]

103. Oda K, Okada J, Timmerman L, Rodriguez-Viciana P, Stokoe D, Shoji K, et al. PIK3CA cooperates with other phosphatidylinositol $3^{\prime}$-kinase pathway mutations to effect oncogenic transformation. Cancer Res. 2008; 68(19):8127-36. [PubMed: 18829572]

104. Castellano E, Downward J. RAS Interaction with PI3K: More Than Just Another Effector Pathway. Genes Cancer. 2011; 2(3):261-74. [PubMed: 21779497]

105. Turke AB, Engelman JA. PIKing the right patient. Clin Cancer Res. 2010; 16(14):3523-5. [PubMed: 20538763]

106. Chappell WH, Steelman LS, Long JM, Kempf RC, Abrams SL, Franklin RA, et al. Ras/Raf/ MEK/ERK and PI3K/PTEN/Akt/mTOR inhibitors: rationale and importance to inhibiting these pathways in human health. Oncotarget. 2011; 2(3):135-64. [PubMed: 21411864]

107. Saal LH, Holm K, Maurer M, Memeo L, Su T, Wang X, et al. PIK3CA mutations correlate with hormone receptors, node metastasis, and ERBB2, and are mutually exclusive with PTEN loss in human breast carcinoma. Cancer Res. 2005; 65(7):2554-9. [PubMed: 15805248]

108. Chakrabarty A, Rexer BN, Wang SE, Cook RS, Engelman JA, Arteaga CL. H1047R phosphatidylinositol 3-kinase mutant enhances HER2-mediated transformation by heregulin production and activation of HER3. Oncogene. 2010; 29(37):5193-203. [PubMed: 20581867]

109. Dave B, Migliaccio I, Gutierrez MC, Wu MF, Chamness GC, Wong H, et al. Loss of phosphatase and tensin homolog or phosphoinositol-3 kinase activation and response to trastuzumab or lapatinib in human epidermal growth factor receptor 2-overexpressing locally advanced breast cancers. J Clin Oncol. 2011; 29(2):166-73. [PubMed: 21135276]

110. Park BH, Davidson NE. PI3 kinase activation and response to Trastuzumab Therapy: what's neu with herceptin resistance? Cancer Cell. 2007; 12(4):297-9. [PubMed: 17936554]

111. Migliaccio A, Di Domenico M, Castoria G, de Falco A, Bontempo P, Nola E, et al. Tyrosine kinase/p21ras/MAP-kinase pathway activation by estradiol-receptor complex in MCF-7 cells. Embo J. 1996; 15(6):1292-300. [PubMed: 8635462]

112. Sanchez CG, Ma CX, Crowder RJ, Guintoli T, Phommaly C, Gao F, et al. Preclinical modeling of combined phosphatidylinositol-3-kinase inhibition with endocrine therapy for estrogen receptorpositive breast cancer. Breast Cancer Res. 2011; 13(2):R21. [PubMed: 21362200]

113. Kang S, Bader AG, Vogt PK. Phosphatidylinositol 3-kinase mutations identified in human cancer are oncogenic. Proc Natl Acad Sci U S A. 2005; 102(3):802-7. [PubMed: 15647370]

114. Vitolo MI, Weiss MB, Szmacinski M, Tahir K, Waldman T, Park BH, et al. Deletion of PTEN Promotes Tumorigenic Signaling, Resistance to Anoikis, and Altered Response to Chemotherapeutic Agents in Human Mammary Epithelial Cells. Cancer Res. 2009 
115. Gupta S, Ramjaun AR, Haiko P, Wang Y, Warne PH, Nicke B, et al. Binding of ras to phosphoinositide 3-kinase p110alpha is required for ras-driven tumorigenesis in mice. Cell. 2007; 129(5):957-68. [PubMed: 17540175]

116. Higgins MJ, Beaver JA, Wong HY, Gustin JP, Lauring JD, Garay JP, et al. PIK3CA mutations and EGFR overexpression predict for lithium sensitivity in human breast epithelial cells. Cancer Biol Ther. 2011; 11(3):358-67. [PubMed: 21124076]

117. Serra V, Scaltriti M, Prudkin L, Eichhorn PJ, Ibrahim YH, Chandarlapaty S, et al. PI3K inhibition results in enhanced HER signaling and acquired ERK dependency in HER2-overexpressing breast cancer. Oncogene. 2011; 30(22):2547-57. [PubMed: 21278786]

118. Albain KS, Paik S, van't Veer L. Prediction of adjuvant chemotherapy benefit in endocrine responsive, early breast cancer using multigene assays. Breast. 2009; 18(Suppl 3):S141-5. [PubMed: 19914534]

119. Lauring J, Cosgrove DP, Fontana S, Gustin JP, Konishi H, Abukhdeir AM, et al. Knock in of the AKT1 E17K mutation in human breast epithelial cells does not recapitulate oncogenic PIK3CA mutations. Oncogene. 2010

120. Chapman PB, Hauschild A, Robert C, Haanen JB, Ascierto P, Larkin J, et al. Improved survival with vemurafenib in melanoma with BRAF V600E mutation. N Engl J Med. 2011; 364(26): 2507-16. [PubMed: 21639808]

121. Prahallad A, Sun C, Huang S, Di Nicolantonio F, Salazar R, Zecchin D, et al. Unresponsiveness of colon cancer to BRAF(V600E) inhibition through feedback activation of EGFR. Nature. 2012; 483(7387):100-3. [PubMed: 22281684]

122. Amir E, Miller N, Geddie W, Freedman O, Kassam F, Simmons C, et al. Prospective study evaluating the impact of tissue confirmation of metastatic disease in patients with breast cancer. $\mathrm{J}$ Clin Oncol. 2012; 30(6):587-92. [PubMed: 22124102]

123. Niikura N, Liu J, Hayashi N, Mittendorf EA, Gong Y, Palla SL, et al. Loss of Human Epidermal Growth Factor Receptor 2 (HER2) Expression in Metastatic Sites of HER2-Overexpressing Primary Breast Tumors. J Clin Oncol. 2012; 30(6):593-9. [PubMed: 22124109]

124. Dupont Jensen J, Laenkholm AV, Knoop A, Ewertz M, Bandaru R, Liu W, et al. PIK3CA Mutations May Be Discordant between Primary and Corresponding Metastatic Disease in Breast Cancer. Clin Cancer Res. 2011; 17(4):667-77. doi:1078-0432.CCR-10-1133 [pii] 10.1158/1078-0432.CCR-10-1133. [PubMed: 20940279]

125. Gonzalez-Angulo AM, Ferrer-Lozano J, Stemke-Hale KA, Sahin AA, Liu S, Barrera JA, et al. PI3K Pathway Mutations and PTEN Levels in Primary and Metastatic Breast Cancer. Mol Cancer Ther. 2011 doi:1535-7163.MCT-10-1089 [pii] 10.1158/1535-7163.MCT-10-1089.

126. Higgins MJ, Jelovac D, Barnathan E, Blair BG, Slater S, Powers P, et al. Improving detection methods for PIK3CA mutations in breast cancer using peripheral blood from patients with metastastic breast cancer (MBC). J Clin Oncol. 2011; 29 (suppl: abstr 10512).

127. Diehl F, Li M, Dressman D, He Y, Shen D, Szabo S, et al. Detection and quantification of mutations in the plasma of patients with colorectal tumors. Proc Natl Acad Sci U S A. 2005; 102(45):16368-73. [PubMed: 16258065]

128. Dressman D, Yan H, Traverso G, Kinzler KW, Vogelstein B. Transforming single DNA molecules into fluorescent magnetic particles for detection and enumeration of genetic variations. Proc Natl Acad Sci U S A. 2003; 100(15):8817-22. [PubMed: 12857956]

129. Diehl F, Li M, He Y, Kinzler KW, Vogelstein B, Dressman D. BEAMing: single-molecule PCR on microparticles in water-in-oil emulsions. Nat Methods. 2006; 3(7):551-9. [PubMed: 16791214]

130. Diehl F, Schmidt K, Choti MA, Romans K, Goodman S, Li M, et al. Circulating mutant DNA to assess tumor dynamics. Nat Med. 2008; 14(9):985-90. [PubMed: 18670422] 


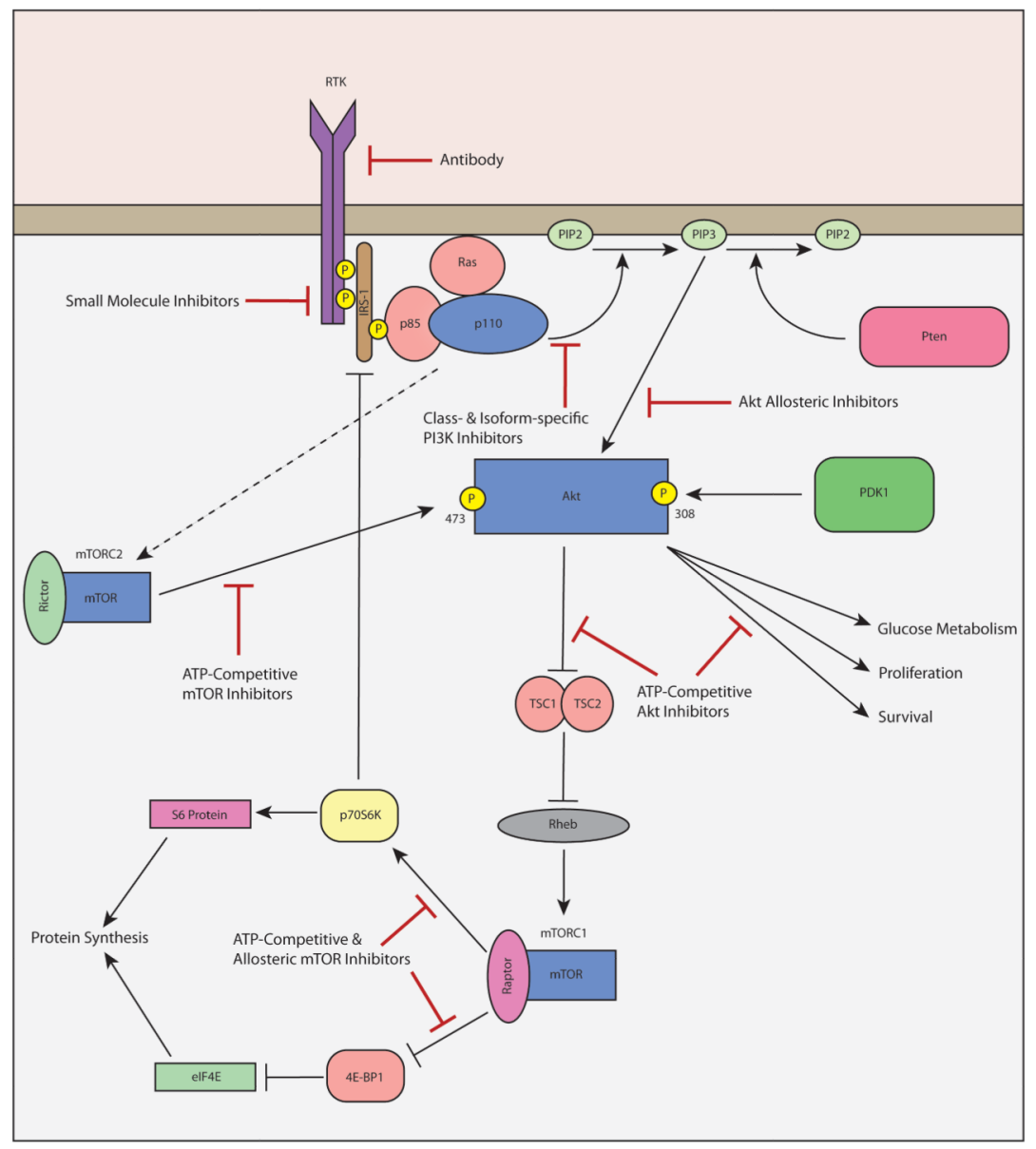

Figure 1.

The PI3K/Akt/mTOR pathway. Activation of a receptor tyrosine kinase (RTK) leads to increased activity of PI3 kinase complexes (p85 and p110) which in turn converts phosphatidylinositol-4,5-bisphosphate (PIP2) to phosphatidylinositol-3,4,5-trisphosphate (PIP3); a reaction that is antagonized by the tumor suppressor Pten. PIP3 then phosphorylates and activates Akt, which through a series of subsequent phosphorylation events leads to activation of the mTOR complexes, mTORC1 and mTORC2. mTOR complexes are also kinases that activate via phosphorylation substrates such as S6 and 4EBP1 that increase transcription of growth promoting genes. Points of pharmacologic inhibition that are currently the focus of drug development are shown. 